\title{
Um procedimento baseado na acessibilidade para a concepçáo de Planos Estratégicos de Mobilidade Urbana: o caso do Brasil
}

Andréa Mello. Centro Federal de Educação Tecnológica Celso Suckow da Fonseca (CEFET), Rio de Janeiro, Brasil.

Licinio Portugal. Universidade Federal do Rio de Janeiro (UfRJ), Rio de Janeiro, Brasil.

RESUmo | A elaboração de um plano de mobilidade urbana comprometido com a sustentabilidade vem sendo defendida em todo o mundo, sendo que a sua formulação representa um desafio conceitual e prático. No Brasil, apesar de ser uma exigência legal, apenas uma parcela irrisória das cidades a atende. Dentre os motivos se alegam dificuldades quanto ao uso das metodologias tradicionais. Nesse contexto, intenciona-se desenvolver um procedimento que estabeleça as bases para a definição de estratégias associadas à acessibilidade com vistas a promoção de uma mobilidade sustentável. A concepção deste procedimento pretende contribuir para superar restriçóes tipicamente observadas nas abordagens convencionais, destacando o conceito de acessibilidade por seu potencial de articulação entre transportes e uso do solo. Procura ser aplicável às especificidades de metrópoles brasileiras. Espera-se assim colaborar para que o Plano de Mobilidade cumpra com a sua missão e seja um instrumento de transformação sintonizado com o interesse público.

PALAVRAS-CHAVE | planejamento urbano, sustentabilidade urbana, mobilidade.

ABSTRACT | The formulation of urban mobility plans committed to sustainability has been advocated throughout the world, but this task presents conceptual and practical challenges. In Brazil, although this is a legal requirement, only a small fraction of cities have developed such plans. Among the excuses given is the difficulty of using the traditional methods. In this context, we describe a procedure that establishes the bases for definition of strategies associated with accessibility, with the aim of promoting sustainable mobility. The conception of this procedure aims to help overcome the restrictions typically observed in conventional approaches, with the accessibility concept standing out for its potential for articulation between transportation systems and land use patterns. We have tailored this procedure to the specific features of large Brazilian metropolitan regions. Our aim is to help mobility planning accomplish its mission and to serve as an instrument for transformation in line with the public interest.

KEYWORDs | urban planning, urban sustainability, mobility.

Recibido el 10 de febrero de 2015, aprobado el 22 de enero de 2016

E-mail: Andrea Mello, andrea.mello@cefet-rj.br | Licinio Portugal, licinio@pet.coppe.ufrj.br 


\section{Introduçáo}

Sustentabilidade tornou-se uma palavra chave nas últimas décadas (Seabra, Taco \& Dominguez, 2013; Silva \& Romero, 2015), que tem inspirado mundialmente o sentimento de mudança. O que é mais visível nas cidades, e nas economias emergentes, onde a população urbana cresce significativamente, tendendo a dobrar entre 2000 e 2030, alcançando quatro bilhóes de habitantes, com demandas por infraestrutura e serviços, cujo atendimento envolve planejamentos estratégicos adaptados a cada realidade (Somik, 2013). O problema é ainda mais crítico considerando o crescimento da taxa de motorização em tais países (que duplicou entre 1990-2000), com tendência de continuar elevada nas próximas décadas (onU-Habitat, 2013).

Portanto, a problemática da sustentabilidade nas cidades está fortemente relacionada aos transportes, que impactam significativamente na qualidade de vida da população (onU-Habitat, 2013; un-Habitat, 2013), tanto por seu papel no desenvolvimento urbano, quanto por causarem externalidades negativas como o alto consumo de energia, os acidentes de trânsito e a emissão de gases de efeito estufa (Souza, 2015). Nos países em desenvolvimento tais efeitos tendem a ser ainda mais severos, principalmente nos segmentos mais pobres (UN-Habitat, 2013).

Diante disso, a mobilidade está cada vez mais presente nas políticas e estratégias territoriais e urbanas (Instituto da Mobilidade e dos Transportes Terrestres [IMTT], 2011), sendo um plano de mobilidade comprometido com a sustentabilidade fundamental nesse processo de mudança. Ao mesmo tempo, sua formulaçáo e implantação representam um desafio conceitual e prático (European Union [EU], 2014; Somik, 2013; Veiga, 2011), acentuado nos países em desenvolvimento, por apresentarem áreas superpopulosas, sistemas de transportes não integrados e baseados nos modos rodoviários (individuais e coletivos), redes viárias especializadas insuficientes e desbalanceamento espacial entre moradia e emprego (Cervero, 2013; Portugal, Florez \& Silva, 2010).

No caso da América Latina e, mais especificamente, do Brasil, várias cidades apresentam essas características, com desigualdades no acesso aos meios de transportes e às oportunidades disponíveis no espaço urbano. Segundo a CEPAL, a América Latina e o Caribe conformam a região menos equitativa do mundo, apesar dos avanços ocorridos a partir do início dos anos 2000 (Programa das Naçóes Unidas para o Desenvolvimento [PNUD], 2010).

Nesse ambiente - em que o planejamento normalmente não é valorizado, não conta com a participaçáo da sociedade e nem é exercido como um instrumento de transformação (Portugal et al., 2010), instituiçóes frágeis são pressionadas por grupos poderosos e influentes na destinação de investimentos públicos, reforçando as diferenças sociais e espaciais (Vasconcellos, 2000). Nessas condiçóes, ressalta-se a necessidade de um planejamento integrado que articule transporte e uso do solo (Gouvêa, 2009), tornando mais equitativa a acessibilidade às atividades requeridas pela população, em particular a mais pobre e com restrições de mobilidade, através das modalidades socialmente mais produtivas.

Nas metrópoles brasileiras, é crescente o número de pessoas que leva cada vez mais tempo nos deslocamentos casa/trabalho/casa, com cerca de $20 \%$ delas gastando mais 
de duas horas neste percurso (Ribeiro, Silva \& Rodrigues, 2014). Há ainda uma alta parcela de longas viagens feitas a pé como reflexo da exclusão social (Portugal et al., 2010), uma taxa de imobilidade elevada em cidades importantes como São Paulo e Rio de Janeiro (Motte-Baumvol \& Nassi, 2012) e um alto índice de acidentes, cujas vítimas, em sua maioria (66\%), são pedestres, ciclistas e motociclistas (Waiselfisz, 2013).

O governo federal - motivado pelas manifestaçôes populares realizadas no país em 2013, que exigiam melhores serviços públicos, principalmente em mobilidade urbana - começou a atuar mais fortemente tanto na regulamentação como na destinação de recursos nesse setor. Esse esforço buscou reverter décadas de abandono da questấo urbana (Rolnik, 2013).

No marco regulatório, a Lei no 12.587/12, denominada Lei Nacional de Mobilidade Urbana (LNMU), estabeleceu a obrigatoriedade de elaboraçáo de Planos de Mobilidade Urbana (PMU) aos municípios com mais de 20 mil habitantes. Quanto à alocação de recursos, disponibilizaram-se vultosos valores para obras ${ }^{1}$ e projetos ${ }^{2}$ de transportes nos últimos anos, dos quais apenas 3,8\%, foram utilizados. Mesma proporção ocorre quanto à realização de Plano de Mobilidade pelos municípios brasileiros: apesar da necessidade explícita e da exigência legal, os Planos não são feitos ou não atendem aos requisitos estabelecidos. ${ }^{3}$

A ausência de uma cultura de planejamento (Rubim \& Leitão, 2013) interfere nessa situação, além de um corpo técnico não valorizado e recursos orçamentários, gerenciais e metodológicos incompatíveis com as suas atribuiçôes (Gemelli \& Filippim, 2010), impulsionando o envolvimento de consultorias no planejamento dos transportes. Essas tendem a usar as metodologias tradicionais que vêm sendo contestadas e criticadas por diversos estudos científicos (Kane \& Del Mistro, 2003; Straatemeier, 2008) e entidades internacionais (onU-Habitat, 2013, Somik, 2013), que evidenciam uma preocupação quanto à necessidade de novas abordagens.

Atualmente há uma perspectiva promissora (Rubim \& Leitão, 2013) com vistas a conscientizar a população e os gestores sobre novos conceitos no planejamento dos transportes, incorporando a sustentabilidade às decisôes técnicas (Azevedo Filho \& Rodrigues da Silva, 2012). O que reforça a criação de abordagens alternativas, que valorizem o diálogo interdisciplinar e uma gestão mais democrática, baseada em métodos exequíveis e condizentes com a realidade brasileira.

Nesse sentido, o presente estudo objetiva contribuir com a promoção de uma mobilidade sustentável através de um procedimento metodológico que estabeleça as bases para a formulação de estratégias associadas a padrôes de acessibilidade a serem implementados, em suas diferentes escalas territoriais, dando destaque ao conceito de acessibilidade, por seu potencial de articulação entre transportes e uso do solo.

1 Disponibilidade de R\$143 bilhôes para projetos de mobilidade urbana em 118 cidades de grande e médio porte nos últimos anos. Disponível em: http://www.antp.org.br/website/noticias/show. asp?npgCode=70756710-A46C-4BD4-AD34-12392B78CB63.

2 Disponibilidade de $\mathrm{R} \$ 12,4$ bilhôes para projetos de transportes das prefeituras e governos estaduais, dos quais, menos de $4 \%$ foram utilizados. Disponível em: http://www.pac.gov.br/ noticia/deb9ae9d

3 Das 5.565 cidades do país, apenas 210 têm plano de mobilidade. Disponível em: http:// greenpeace.org.br/cade/ 


\section{Revisão de Literatura -}

\section{Críticas ao Planejamento dos Transportes Baseado na Abordagem Tradicional}

A abordagem tradicional de planejamento dos transportes - que segundo alguns autores pouco difere na essência da que surgiu nos anos 1950 e 1960 (Kane \& Del Mistro, 2003) - segue a ideia de previsão da demanda futura e da provisão dos recursos necessários para atendê-la com mais infraestrutura (Herce, 2009), cuja viabilidade econômica associa-se à redução de custos operacionais e/ou do tempo de viagem (Azevedo Filho \& Rodrigues da Silva, 2012).

Porém, além de mascarar o problema temporariamente, esse tipo de abordagem desconsidera custos de mensuração mais complexa, como aqueles relativos aos impactos ambientais (Banister, 2011), e restringe a concepção integrada entre transporte e uso do solo, ignorando a interdependência que existe entre eles (Herce, 2009; Waddell, Ulfarsson, Franklin \& Lobb, 2007). Embora envolva técnicas avançadas e sofisticadas, com apropriação de dados da pesquisa origem-destino e de modelagem matemática, utilizando-se de recursos financeiros, computacionais e de pessoal especializado, elas até hoje não são usadas, consistentemente, em muitas cidades do mundo (Frederico, 2001). E nos países em desenvolvimento, como o Brasil, seu uso se mostra ainda mais problemático devido a uma realidade distinta daquela onde as mesmas foram originadas, e pelos recursos requeridos muitas vezes não estarem disponíveis.

Outra crítica refere-se à falta de um processo decisório participativo (Fouracre, Sohail \& Cavill, 2006). No caso brasileiro, a Lei de Mobilidade Urbana tenta minimizar esse problema prevendo a possibilidade de participação popular na criação e validação do plano de mobilidade, para proporcionar maior transparência e legitimidade.

Apesar das críticas à abordagem tradicional, há um reconhecimento quanto ao seu mérito, até por sua frequência de uso. Portanto, evidenciá-las permite identificar lacunas a serem trabalhadas com o intuito de superá-las e embasar novas abordagens. Essa mudança requer uma visão mais abrangente, que incorpore um olhar integrado e multimodal da mobilidade urbana (Straatemeier, 2008; Waddell et al., 2007). Realçar o papel da acessibilidade é, sem dúvida, uma das principais açôes necessárias para que uma mobilidade mais sustentável possa ser atingida (Banister, 2008), porque amplia a gama de soluçóes possíveis tanto pelo conceito de acessibilidade já expressar o compromisso com a integração transporte/uso do solo (European Commission, 2013; Halden, 2002) como por envolver também as telecomunicaçóes, extrapolando medidas clássicas que interferem no fluxo de viagens (Litman \& Brenman, 2012).

Nessa direção, estudiosos da área de transportes têm apontado para uma mudança de paradigma em andamento (Banister, 2011; Litman \& Brenman, 2012), onde a mobilidade, percebida pelos seus aspectos quantitativos, abre espaço para seus componentes qualitativos (Litman, 2008). Além disso, realça-se a necessidade de um planejamento integrado, onde a influência dos transportes sobre a organização do território não seja ignorada (Herce, 2009; Rivas, 2014). Como também a busca por uma concepção mais simples, exequível, flexível e aderente às especificidades locais, com princípios e elementos que incentivem a participação dos atores intervenientes no processo de decisão (Vega, 2011). 


\section{Planejamento Integrado dos Transportes: abordagens alternativas e o papel da acessibilidade}

A partir do maior comprometimento com a sustentabilidade, surgiram, para os planejadores dos transportes, desafios distintos dos habituais (Kane \& Del Mistro, 2003) e mais complexos (Jeppesen, 2009), explicitando as restriçóes do modelo tradicional e fazendo prosperar abordagens alternativas.

$\mathrm{Na}$ revisão da literatura identificaram-se pelo menos três vertentes que podem ser consideradas:

- a que trabalha com ferramentas adicionais (como o método de análise hierárquica, técnicas prospectivas como a Delphi e/ou de análise multicritério) para incentivar a participação de atores intervenientes, embora amparada no modelo tradicional (Fierek \& Zak, 2012);

- a que privilegia o planejamento urbano integrado do transporte, uso do solo e desenvolvimento baseado no uso de softwares mais sofisticados, como os simuladores urbanos itLup, UrbanSim, MEPLAN e o TRANUS, estendendo a abrangência da complexidade investigada (Waddell, et al., 2007);

- a que destaca a importância de um planejamento integrado e intersetorial dos transportes associada a procedimentos menos complexos (Curl, Nelson, \& Anable, 2011; Herce, 2009; Hull, 2005; Rivas, 2014).

Esta última vertente, apesar de valorizar a simplicidade, possui uma perspectiva comprometida com a visão abrangente, integrada e interdisciplinar do planejamento dos transportes, compreendendo estudos com ênfase:

- em modelos mais participativos de planejamento dos transportes (Fouracre et al., 2006; Franceschini \& Maletto, 2014), que procuram acomodar necessidades políticas, sinergias e abordagens mais recentes para a gestão urbana, envolvendo perspectivas de diversos atores, de forma que, a partir de diálogos e/ou consultas públicas, por exemplo, surjam insights e apreciaçóes mais profundas das questôes tratadas (Kane \& Del Mistro, 2003), permitindo que haja aprendizagem ao longo do processo;

- na oferta da infraestrutura e serviços de transporte integrados com o planejamento territorial (Herce, 2009; Levinson, 2012; Rivas, 2014). Dentro dessa perspectiva, o efeito das redes de infraestrutura, de uma maneira geral, sobre os territórios funcionam como um elemento de organização espacial, definindo estratégias territoriais e econômicas de desenvolvimento, além de influenciar o comportamento espacial da mobilidade e da localização de atividades (Herce, 2009; Rivas, 2014);

- em indicadores de desempenho de redes de transportes, como a acessibilidade, para lidar com a localização das atividades no território e sua relação com cenários que expressam os objetivos e a mobilidade desejados (Curl et al., 2011; Parthasarathi, 2014).

As três ênfases podem ser consideradas com a pretensão de aperfeiçoamento da abordagem convencional, e as duas últimas possuem características próximas, 
baseando-se na oferta de infraestrutura e de serviços de transportes, cujos indicadores de desempenho permitem uma articulação com o uso do solo, preocupando-se com a integração entre eles. E possibilitam estabelecer a relação espacial entre estes indicadores de acessibilidade e de centralidade com os de mobilidade e desenvolvimento sustentáveis nas diferentes localidades do território urbano (Herce 2009).

Entende-se que o foco na oferta amplia o escopo de análise, considerando a multimodalidade a ser atendida e o alcance espacial associado a cada uma delas para desfrutar de uma atividade, justificando as múltiplas escalas de análise em contextos mais complexos (Rivas, 2014).

Nessa direção também está amparado o conceito de acessibilidade sustentável (Cheng, Bertolini \& Le Clercq, 2007; Curtis, 2008), pois lida com a interação entre estes elementos a fim de respaldar novos padróes de deslocamento, envolvendo a organização das atividades no espaço urbano para torná-las mais acessíveis e infraestruturas de transportes favoráveis ao uso das modalidades mais amigáveis ao meio ambiente (Geurs \& Wee, 2004), bem como pela equidade no acesso a oportunidades, capazes de influir na escolha do modo e da frequência dos deslocamentos (Vega, 2011).

Nesse sentido, o planejamento do uso do solo e dos transportes, de maneira interativa, envolve pensar no planejamento da acessibilidade (Cascetta, Cartenì \& Montanino, 2013), pois esta se refere à facilidade com que atividades urbanas podem ser alcançadas a partir de determinada origem ou por determinados indivíduos em dada localidade (Levinson, 2012; Litman, 2015). Mas também a forma como a acessibilidade deve ser projetada para ser um eficiente instrumento de promoção da mobilidade sustentável.

Alinhado com essa visão, o presente estudo ressalta a importância de uma abordagem em que a acessibilidade esteja orientada à mobilidade sustentável na construção e avaliação de cenários para respaldar o processo decisório. A acessibilidade, tratada dessa forma, tem a vantagem de permitir mapear distintas realidades numa mesma regiáo metropolitana, respeitando as especificidades existentes. Curl et al. (2011) e Litman (2015), por exemplo, estudam este conceito e maneiras de incorporá-lo ao planejamento integrado de transportes, reconhecendo o tamanho deste desafio, pela multiplicidade de aspectos envolvidos apresentada, esquematicamente, na figura 1 .

Estes elementos reforçam tanto a relevância do conceito de acessibilidade para atender as exigências requeridas por um planejamento integrado como, devido à sua amplitude e variedade de componentes, a necessidade de organizá-la e estruturá-la para ser incorporada ao planejamento. Portanto, apesar da acessibilidade e da mobilidade terem significados distintos (Handy, Cao \& Mokhtarian, 2005), seu vínculo é extremamente forte, e tais sutilezas conceituais justificam melhor entender estes dois conceitos, a relaçáo entre eles (Raia Jr., 2000) e o Plano de Mobilidade, em particular, quando o compromisso é com a sustentabilidade. 
FIGURA I | A acessibilidade e suas diferentes perspectivas

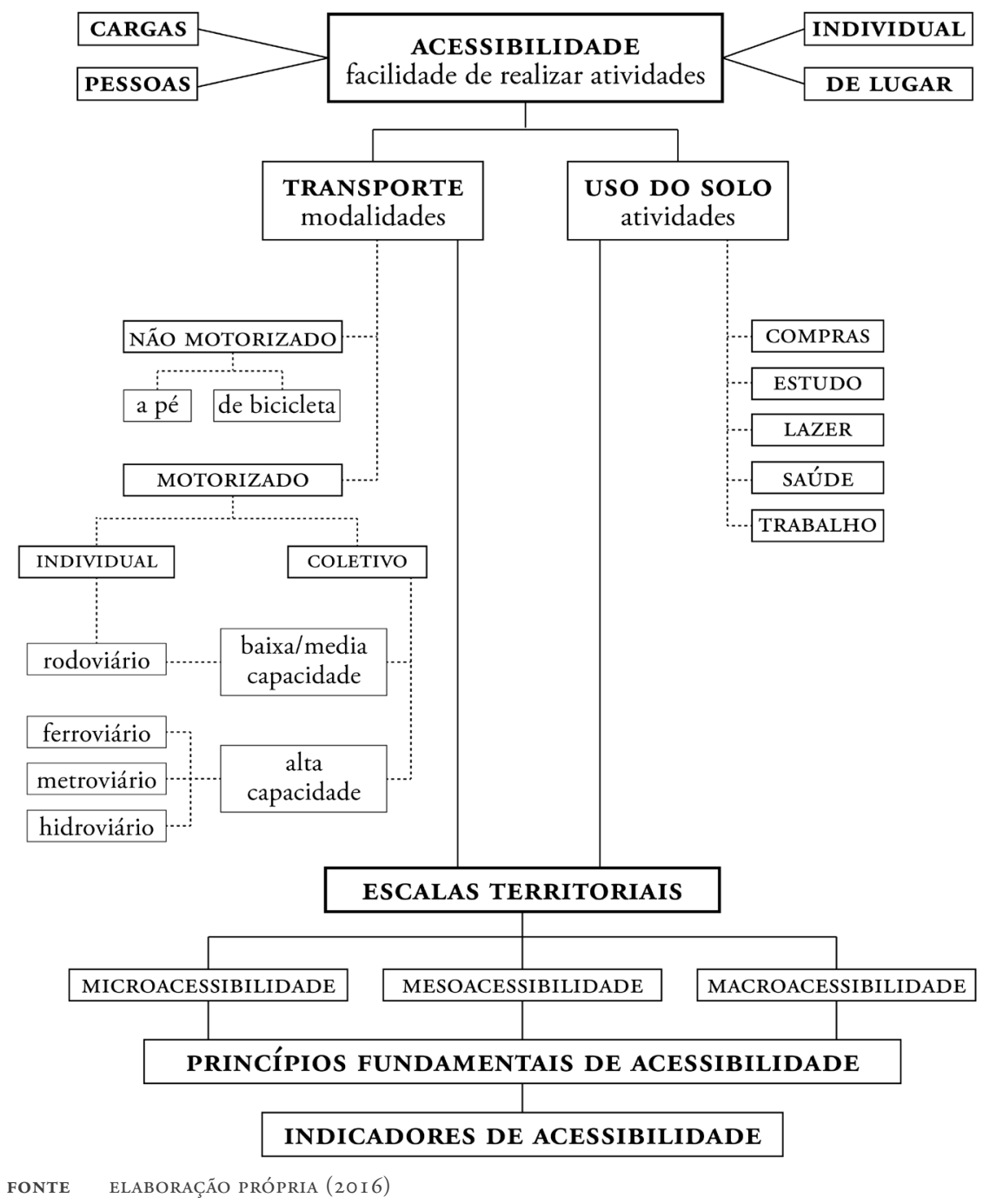

\section{Plano de Mobilidade baseado em acessibilidade comprometido com a sustentabilidade: uma concepçáo para o caso do Brasil}

As cidades brasileiras vivem um momento de crise da mobilidade urbana, resultante, sobretudo, da valorizaçáo do transporte motorizado individual em detrimento do coletivo (Ribeiro et al., 2014), do negligenciamento do transporte não motorizado, da falta de integração entre as modalidades (Gonçalves, Portugal \& Nassi, 2009) e da desarticulação entre planejamento urbano e de transportes (Costa, 2008). 
Esta situação se acentua pelo quadro de desigualdades existente no Brasil, mesmo diante da reduçáo da pobreza e das disparidades, de uma maneira geral, entre as regióes metropolitanas. Entretanto a desigualdade no interior das metrópoles ainda é marcante (Pochmann, 2010; PNUD, 2014) e se reproduz na distribuição espacial das atividades ao longo do território, concentrando-se prioritariamente em áreas mais centrais, com melhor infraestrutura e onde se encontra a população com mais recursos (Portugal et al., 2010).

Os empregos seguem essa lógica (Ribeiro et al., 2014), impondo aos trabalhadores longos e radiais percursos diários. Mas, diferentemente das práticas internacionais bem sucedidas, esta demanda, em muitos corredores, não é atendida pelos sistemas de transportes de maior capacidade, como o metroferroviário. Pior, em alguns casos, como no Rio de Janeiro, mais de $220 \mathrm{~km}$ de ferrovia são subutilizados, transportando menos de $25 \%$ de sua capacidade potencial, enquanto ao lado, operam corredores rodoviários saturados, contrariando qualquer critério técnico (Gonçalves et al., 2009).

A desigualdade acentua-se pela falta de uma rede estruturante que cubra todo o território de forma equitativa e pelo fato dos ramais ferroviários operarem com baixa qualidade de serviço, cujas estaçóes, principalmente nas regióes mais pobres e periféricas, não são conectadas por linhas alimentadoras de transporte de menor capacidade ou por facilidades para os pedestres e ciclistas (Portugal et al., 2010; ONU-Habitat \& CAF, 2014).

Isso realça a necessidade de mudança de paradigma, que permita uma visão integrada, com instrumentos de gestáo urbanística, subordinados aos princípios da sustentabilidade e voltando-se decisivamente para a inclusão social (Ministério das Cidades, 2015). E apesar do avanço, embora tímido, proporcionado pela já citada LNMU, em 2012, a temática é uma novidade na agenda da maioria das prefeituras, especialmente para as dos municípios com menos de 500 mil habitantes.

Para estimular e orientar os municípios no processo de elaboração dos PMU, o Ministério das Cidades disponibiliza um Caderno de Referência onde se apresenta um conjunto sistematizado de informaçóes sobre os elementos que constituem o planejamento da mobilidade, os métodos de trabalho e o processo de planejamento. O Caderno é importante na formulação de princípios e conceitos que devem ser contemplados, e também descreve as atividades que devem ser seguidas na elaboração do Plano, sendo uma delas a "Metodologia a ser empregada". Mas, quanto a essa Metodologia, o Caderno é pouco efetivo na fundamentação de como proceder, pois, ao contrário de guias europeus (eU, 2013) e de outros países (Department of Rail and Public Transportation [DRPT], 2013; Nsw [New Sourh Wales] Government, 2013), ele não enfatiza um planejamento integrado do uso do solo e dos transportes e ainda trabalha sob o prisma da abordagem tradicional.

Apesar das iniciativas que vêm sendo implementadas no sentido de apoiar a elaboração de tais Planos (EU, 2014; GIZ, 2014), a UN-Habitat (2013) considera que o guia por ela proposto é apenas um ponto de partida para uma análise geral da mobilidade urbana, diante da urgência de países, como o Brasil, em alterar o seu padrão de desenvolvimento e sua relação com o transporte urbano (Libardi, 2014). 
Segundo alguns estudos (imtт, 2011; giz, 2014), o Plano de Mobilidade é um instrumento que estabelece as estratégias quanto à organização das acessibilidades e gestão da mobilidade, definindo um conjunto de medidas que contribuam para a implementação e promoção de um modelo de mobilidade mais sustentável, que nos países mais desenvolvidos procura ser: (i) compatível com o desenvolvimento econômico; (ii) indutor de uma maior coesão social; e (iii) orientado para a proteção do ambiente e eficiência energética.

No Brasil e demais países da América Latina, há, adicionalmente, outras preocupaçôes, como a redução da desigualdade e a promoção da inclusão social (ONUHabitat \& CAF, 2014), reforçando o papel da equidade e da integração. O mesmo com a segurança de trânsito (Cervero, 2013), como contraponto à violência, reflexo da desigualdade que também ocorre no uso do espaço público, como o sistema viário (Portugal et al., 2010). Estes objetivos devem ser também contemplados na formulação da acessibilidade na busca pela mobilidade sustentável.

Naturalmente, o PMU, baseado na acessibilidade comprometida com a mobilidade sustentável, pressupóe que as pessoas disponham de condiçóes que proporcionem deslocamentos com segurança, conforto, em tempos/custos aceitáveis, e com a maior eficiência energética e menos impactos ambientais (IMTT, 2011). Para isto, a acessibilidade deve ser direcionada a integraçáo e valorizaçáo do transporte público e do não motorizado, reduzindo recursos e espaços destinados ao transporte individual (Hull, 2005; Rivas, 2014). Mas para tornar mais visível a relação entre a acessibilidade e a mobilidade, é importante que tais conceitos sejam caracterizados de acordo com os princípios de sustentabilidade, mas segundo um formato que compreenda sua complexidade, sem prejudicar a sua aplicabilidade. Portanto, torna-se requerido determinar:

- Que mobilidade queremos?

- Que padróes de acessibilidade devem ser fornecidos para proporcionar a mobilidade sustentável e como modelá-los?

\section{Caracterizaçáo da mobilidade sustentável e seus atributos}

A medição tradicional da mobilidade ressalta, principalmente, a quantidade de viagens, valorizando modalidades mais rápidas, e, consequentemente, o uso de automóveis (Litman, 2015). Mas quando conectada com a questão da sustentabilidade, outros atributos se destacam, como: a segurança (Forum of European Road Safety Institute/European Conference of Transport Research Institutes [FERSI/ECTRI], 2009; Wei \& Lovegrove, 2012), a eficiência energética e no uso de outros recursos (GIZ, 2014), a redução de emissões de gases de efeito estufa (Abdallah, Belloumi \& De Wolf, 2013; Nelldal \& Anderson, 2011), a redução da exclusão social (onU-Habitat \& CAF, 2014), o incremento na qualidade de vida (Jeon, Amekudzi \& Guensler, 2013). Tais atributos costumam ser derivados das três dimensóes tradicionais da sustentabilidade: econômica, social e ambiental (IмтT, 2011; European Commission, 2013). 
Considerando a literatura pesquisada e as características típicas das cidades brasileiras, cinco atributos são selecionados para expressar o que se deseja como mobilidade sustentável, ou seja, ser:

a. Produtiva: envolve um uso mais eficiente dos recursos energéticos (Western Australian Planning Commission [WAPC], 2012) e mais racional da infraestrutura de transportes disponível direcionada às modalidades de maior capacidade e mais efetivas em atender a demanda de viagens, integradas aos demais modos, incluindo a utilização do espaço viário, que também é um bem público e limitado, priorizando as modalidades coletivas e protegendo as mais vulneráveis;

b. Inclusiva: representa condiçôes que permitam o atendimento universal das necessidades de viagens, em especial daqueles com restriçóes físicas e de renda (Adley \& Halden, 2013). Embora a inacessibilidade ou isolamento náo seja, geralmente, considerado no planejamento de transporte (Litman, 2015), deve ser levada em conta, pois pode ser um sinal de exclusão para os mais pobres, o que viola o direito à cidadania e torna a imobilidade algo inadmissível;

c. Segura: garante o compromisso com a saúde, a integridade e o direito à vida e ocorre em condiçóes seguras, com menos riscos, conflitos, acidentes e mortes nas viagens e particularmente no trânsito (FERSI/ECTRI, 2009; Litman \& Fitzroy, 2015);

d. Justa socialmente: apresenta qualidade de serviço para todos e se realiza com tempos aceitáveis, principalmente, nas viagens a trabalho e ao ensino, proporcionando condições das pessoas desfrutarem outras atividades e oportunidades, fundamentais para a qualidade de vida e o bem estar social (Welch \& Mishra, 2013);

e. Verde: pressupóe o compromisso com viagens baseadas em meios de transportes amigáveis ambientalmente, com energia limpa e em condições focadas na redução da poluição atmosférica, sonora, das emissóes de gases de efeito de estufa (Porter et al., 2013).

\section{Caracterização e estruturação da acessibilidade orientada a mobilidade} sustentável: escalas territoriais

A acessibilidade está no centro das preocupaçóes para se alcançar uma forma urbana que seja ambientalmente sustentável, socialmente equitativa e inclusiva (onU-Habitat, 2013). A tendência é a dos territórios se organizarem em diversas escalas, com base numa rede de centralidades, que exigem condiçóes de acessibilidade adequadas (IмTT, 2011). Na medida em que a acessibilidade é uma poderosa medida utilizada na análise espacial, há uma preocupação com a escolha da escala territorial apropriada a seus objetivos (Zhou, Wang \& Schweitzer, 2012) e o mesmo ocorre quando o que se quer é estabelecer as estratégias direcionadas à acessibilidade em busca de uma dada mobilidade.

Inicialmente, as escalas diferenciam-se pela sua extensão geográfica, variando de uma área mais restrita, denominada como escala local (Spiekermann et al., 2011), de vizinhança (Libardi, 2014), ou microscópica (Jones \& Lucas, 2012), ou mesmo de quadra ou de edificação (Balta, Tekel \& Tekel, 2012), até uma área mais abrangente, 
conhecida como escala global (Spiekermann et al., 2011), de nível estratégico (Jones \& Lucas, 2012), regional (Hickman, Seaborn, Headicar \& Banister, 2010) ou macroscópica (Zegras, 2005), intermediadas pela escala mesoscópica (Zegras, 2005).

Nesse estudo, entende-se que a escala global abrange a acessibilidade aqui denominada como macroscópica e que a escala local admite pelo menos duas configuraçôes distintas, denominadas como microscópica e mesoscópica, dependendo do tamanho da área considerada (figura 2).

A escala macro abrange toda a região metropolitana e seu principal requerimento é a disponibilidade de redes de transportes adequadas (Jones \& Lucas, 2012), com a integração multimodal (Spiekermann et al., 2011), para promover maior facilidade de acesso aos destinos (Vasconcellos, 2000) e maior equidade (onU-Habitat \& CAF, 2014), fruto da distribuição espacial da acessibilidade proporcionada pela rede estrutural de transporte público de maior capacidade.

FIGURA 2 Requerimentos em transportes e uso do solo das escalas territoriais

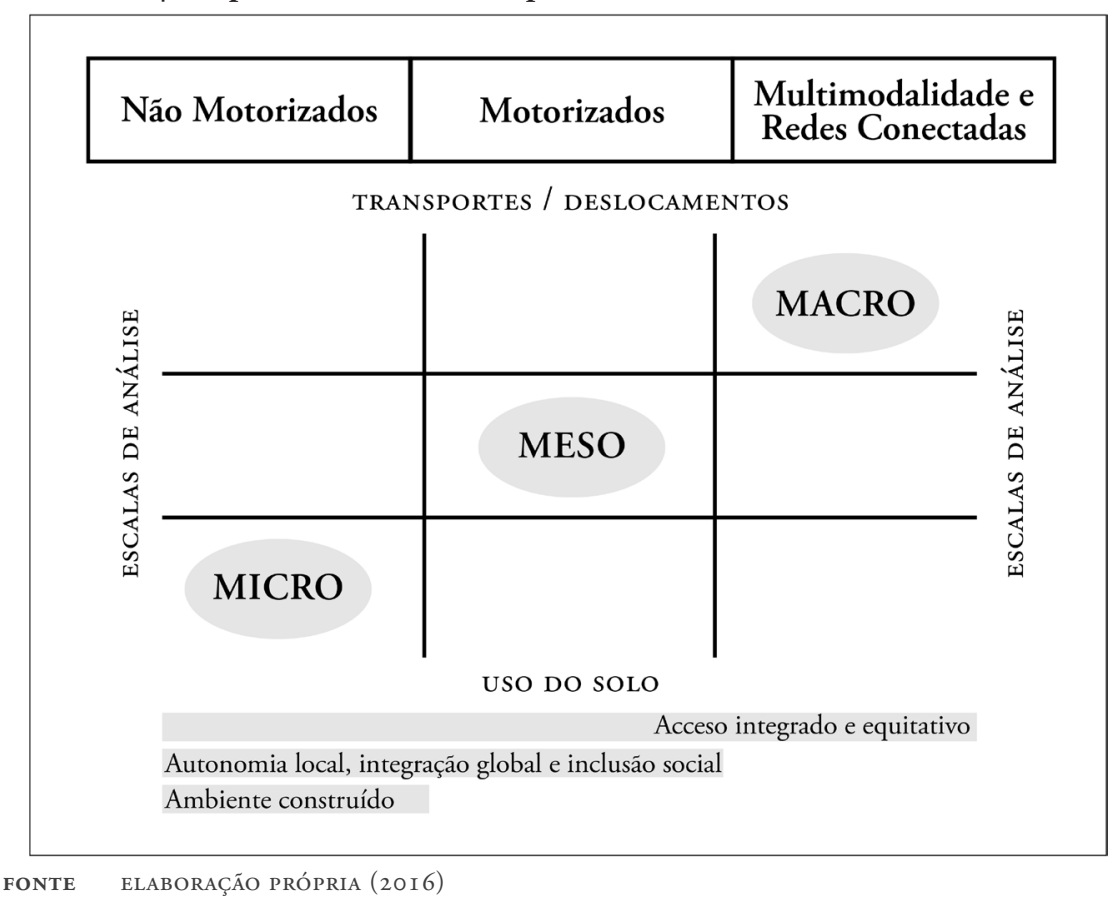

A escala microscópica permite que a acessibilidade ocorra a pé ou mesmo por bicicleta, tornando-a sensível ao ambiente construído, tipicamente representado por: densidade e diversidade de uso do solo, desenho urbano, disponibilidade de transporte público e destinos acessíveis (Cervero, Sarmiento, Jacoby, Gomes \& Neiman, 2009). Enquanto a escala mesoscópica, pela sua maior extensão, inclui também os meios motorizados de transportes, referindo-se tipicamente a um bairro, a uma região administrativa ou mesmo a um município periférico, dependendo tanto do tamanho e da forma da metrópole quanto da densidade da rede estrutural. 
Em conformidade com os objetivos da sustentabilidade, a delimitação das localidades nas escalas meso ou micro, que configuram o território urbano em análise, assume um papel fundamental, ao determinar os locais com autonomia, mas integrados aos demais. Deve ser estabelecida em sintonia com as diretrizes do plano diretor e, desejavelmente, seguir critérios para a construção de cenários que reflitam o interesse público, um projeto de desenvolvimento para a cidade (ou metrópole) e estimulem a participação dos atores intervenientes (GIZ, 2014).

Esse detalhamento é crucial para o planejamento do uso do solo e de uma rede de transportes com capacidade de prover acessibilidade em todas as escalas num padráo sustentável (Curtis, 2008).

\section{Estrutura do procedimento proposto}

A pretensão de elaborar um procedimento que sistematize os conceitos de acessibilidade e mobilidade comprometidos com a sustentabilidade - além de explicitar a relação entre eles como base para a formulação de estratégias - é um desafio para a comunidade científica, e este artigo contribui de maneira exploratória. Sua concepção considera características como: a simplicidade, a flexibilidade em aderir às especificidades locais, buscando colaborar para que o Plano de Mobilidade cumpra com a sua missão.

Nesse contexto, a organização espacial da acessibilidade em escalas territoriais e o papel de cada uma delas - apesar de fundamentados na bibliografia disponível e permitirem uma visão abrangente, integrada e multimodal - podem ser estabelecidos a partir das técnicas de construçáo de cenários assim como a própria caracterização da mobilidade sustentável e de seus atributos.

Por outro lado, a representação destes elementos (mobilidade sustentável e acessibilidade) por meio de apropriados indicadores, além de seguir a abordagem adotada, procura usar mediçóes realísticas e factíveis, apesar da escassez de dados, normalmente encontrada em cidades brasileiras. A formulação destes dois conceitos e a sua conexão podem ser então estruturados, conforme objetivo desta pesquisa.

\section{Mobilidade sustentável e seus indicadores}

A preocupação mais recente com o tema da mobilidade sustentável e com o desenvolvimento de índices para expressá-la é revelada em diversas pesquisas (Banister, 2011; Litman, 2015; Machado, 2010; Rodrigues da Silva et al., 2015), que tipicamente envolvem múltiplos aspectos, trazendo consigo uma complexidade que pode proporcionar um obstáculo à intenção de facilitar o processo de análise. É desejável, portanto, um índice mais robusto, compreendendo uma quantidade menor de aspectos e indicadores (Machado, 2010), mas mantendo a sua capacidade de representar a mobilidade sustentável.

A figura 3 apresenta - a partir das dimensôes da sustentabilidade - alguns indicadores que refletem os cinco atributos sugeridos anteriormente, na tentativa de conciliar a simplicidade de aplicação deste procedimento com a compatibilidade à realidade das cidades brasileiras. Esses indicadores servem para exemplificar a natureza dos mesmos, expressando o padrão de viagens em cada localidade e apontando 
possíveis estratégias a serem indicadas, compreendendo modalidades e atividades socioeconômicas a serem alteradas.

A representação da mobilidade sustentável em cinco atributos e, a partir destes, a definição de indicadores normalmente disponíveis nas metrópoles brasileiras e nas pesquisas de O-D, podendo ser utilizados em diferentes escalas territoriais, configuram fatores fundamentais para o procedimento proposto e o sucesso de sua aplicação.

FIgURA 3 | Exemplos de indicadores e de atributos de mobilidade sustentável

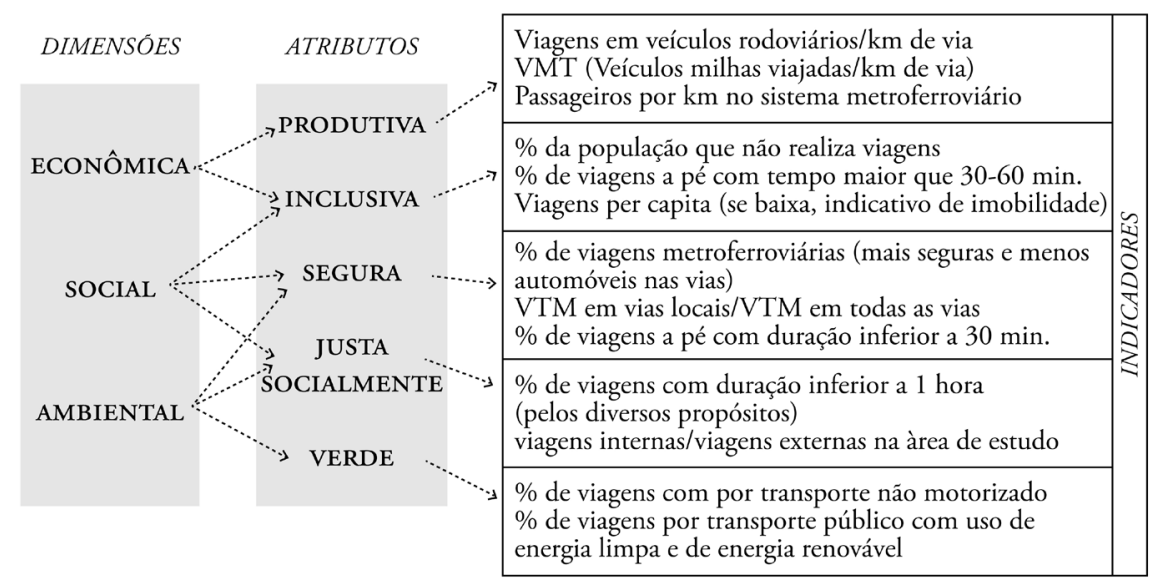

FONTE ELABORAÇÃO PRÓPRIA (20I6)

\section{Acessibilidade orientada a mobilidade sustentável e seus indicadores}

Apesar da variedade de situaçôes e propósitos dificultar, habitualmente, a seleção dos indicadores de acessibilidade (Handy \& Niemeier, 1997), a simplicidade e facilidade de aplicação justificam essa escolha. Como o planejamento baseado em acessibilidade é ainda, relativamente, recente, a aplicação específica destes indicadores exige criatividade e critérios por parte dos analistas (Litman, 2015).

Embora existam diferentes indicadores de acessibilidade usados na análise de estratégias de integração transporte/uso do solo (Geurs \& Wee, 2004), que devam ser contemplados nessa seleção, considerando cada uma das escalas territoriais, algumas indicaçóes são apresentadas como sugestão, a seguir, devendo ser ajustadas às características de cada metrópole.

Para a escala macroscópica sugere-se o uso dos indicadores simples e inspirados em Hansen (1959), que possam refletir a influência da disponibilidade de infraestrutura de transporte público e medir o grau de equidade proporcionado por ela para as diferentes localidades que compóem o território (Welch \& Mishra, 2013). $\mathrm{O}$ mesmo se aplica aos indicadores de acessibilidade que possam incluir também a influência das atividades disponíveis em cada localidade, tornando a representaçáo da acessibilidade mais compatível com o desejo de modelar a integraçáo transporte/ uso do solo. Os indicadores expressos nas Equaçôes 01 e 02 são algumas alternativas (Raia Jr., 2000; Reggiani, Bucci, Russo, Haas \& Nijkamp, 2011). 


$$
A_{I T P}^{i}=\sum_{j=1}^{n} T_{i j}
$$

Onde:

$A_{I T P}^{i}$ - macroacessibilidade da localidade i, proporcionada pela infraestrutura de transporte público;

$T_{i j}$ - expressa o tempo despendido entre a localidade i e as demais $\mathrm{n}$ localidades $\mathrm{j}$ da área estudada.

$$
A_{\text {Serv }}^{i}=\sum_{j=1}^{n} S_{j} T_{i j}
$$

Onde:

$A_{\text {Serv }}^{i}-$ macroacessibilidade da localidade i proporcionada pela infraestrutura de transporte para uma dada oportunidade ou serviço $S$.

$S_{j}$ - expressa a disponibilidade de oportunidades ou serviços nas $\mathrm{n}$ localidades j;

$T_{i j}$ - expressa o tempo despendido entre a localidade i e as demais $\mathrm{n}$ localidades $\mathrm{j}$ da área estudada.

Nestes dois indicadores, quanto maior for o valor encontrado, pior é a integração da localidade i com os serviços ou oportunidades distribuídas pelo espaço metropolitano, sugerindo a necessidade de melhorar o desempenho da rede estruturante de transporte público e de considerar a implantação de novas atividades no local para favorecer a acessibilidade. A amplitude e o desvio padrão referentes aos valores para todas as localidades expressam a dispersão existente e, consequentemente, o nível de potencial desigualdade no território analisado.

Assumindo-se que a acessibilidade é capaz de propiciar os elementos que contribuam para a mobilidade sustentável, a macroacessibilidade, ao depender de uma rede estrutural de transporte público de maior capacidade, qualificada, integrada às demais modalidades e cobrindo o território de forma equitativa, interfere na propensão ao uso de modos coletivos mais produtivos socialmente (Cervero \& Arrington, 2008), como também colabora para retirar automóveis das vias públicas, tornando-as menos congestionadas, menos poluentes e mais seguras pela redução do número de acidentes de trânsito (Hickman et al., 2010). Além da ênfase ao transporte público contribuir para a inclusão (Farrington \& Farrington, 2005) e a justiça social (Martens, 2006), bem como para a qualidade de vida (Delbosc \& Currie, 2011).

Em relação à escala mesoscópica, a acessibilidade deve garantir, por um lado, a integração com a rede estruturante, o que depende de uma malha viária conectada para incentivar os deslocamentos não motorizados, bem como de uma oferta suficiente e qualificada de transporte público, baseada nas modalidades de menor capacidade, para atender as viagens internas e para alimentar as estaçóes que fazem parte de tal rede estruturante (Ministério das Cidades, 2006).

Além disso, a proximidade entre atividades e moradias também tem importância (Levine, Grengs, Shen \& Shen, 2012) assim como a densidade de ambas (Zegras, 
2005) para a acessibilidade e, consequentemente, para a autonomia e o desenvolvimento do lugar, promovendo maior equilíbrio e permitindo que trabalhadores e consumidores atendam suas necessidades diárias sem realizar grandes deslocamentos. O que aumenta a eficiência local e a equidade global (Gordon, Kumar \& Richardson, 1989).

As Equaçóes 03 e 04 apresentam indicadores propostos para a escala mesoscópica, sendo que o primeiro reflete uma preocupação com a garantia de oferta de transporte público qualificada e suficiente (Mavoa, Witten, McCreanor \& O’Sullivan, 2012), além de integrada à rede estruturante que deve cobrir o território urbano, e o segundo preocupa-se com a oferta de atividades condizente às necessidades populacionais (Cervero, 1989). Enfatizando a importância do uso do transporte público e de modalidades sustentáveis, sugerem-se também indicadores que reflitam o nível de restrição à circulação e/ou ao estacionamento de automóveis na área $\left(A_{\mathrm{RA1}}^{i}\right)$.

$$
A_{O T P}^{i}=\frac{O_{T P i}}{P_{i}}
$$

Onde:

$A_{\text {OTP }}^{i}$ - mesoacessibilidade dada pela qualidade e suficiência da oferta de transporte público para atender aos deslocamentos internos da localidade i;

$O_{T P i}$ - expressa a qualidade e quantidade ofertada de transporte público para atender aos deslocamentos internos da localidade i;

$P_{i}$ - expressa o porte das necessidades de viagens internas da localidade i (Ex: população ou superfície).

$$
A_{O S}^{i}=\frac{O_{S i}}{P_{i}}
$$

Onde:

$A_{\text {OS }}^{i}$ - mesoacessibilidade dada pela disponibilidade de serviços e oportunidades na regiáo i em consonância com as necessidades populacionais;

$O_{S i}$ - expressa a disponibilidade de serviços e oportunidades na região i (Ex: número de empregos);

$P_{i} \quad$ - expressa o porte das necessidades de serviços e oportunidades na região i (Ex: população ou quantidade de moradias).

Embora essa combinação entre disponibilidade de oportunidades e serviços versus infraestrutura de transportes adequada seja fundamental em todas as escalas, essa percepção fica mais evidente no tocante à escala microscópica. Isso porque a microacessibilidade está relacionada ao ambiente construído, criando condiçóes de acesso às atividades favoráveis à caminhada e ao uso da bicicleta (Vasconcellos, 2000; Zegras, 2005; Cervero et al., 2009; IмTт, 2011; Institute for Transportation \& Development Policy (ITDP), 2014). E mais, permitindo contato imediato dos habitantes com as atividades (Ministério das Cidades, 2006), através da realização de viagens mais 
curtas e mais frequentes (Litman, 2009), com ganho de tempo e eficiência principalmente pelos modos não motorizados (Cervero et al., 2009). Além de se reduzir a mobilidade motorizada, também pode-se reduzir a necessidade de viagens (Potter \& Skinner, 2000), trazendo benefícios ambientais, promovendo maior equidade e inclusão social, e, concomitantemente, maior dinamismo econômico.

As cinco dimensôes (5 D's) do ambiente construído são fatores estratégicos (Cervero et al, 2009; Handy et al., 2005; GTZ, 2006; Hickman et al., 2010; Iacono, Krizek \& El-Geneidy, 2010) que contribuem com o planejamento do desenvolvimento local. As altas densidades, por exemplo, são importantes porque geram o suporte necessário para o transporte público ser mais eficiente e as atividades mais próximas, enquanto a diversidade está relacionada à combinação e complementaridade apropriada de imóveis, comércio, serviços, escritórios, oportunidades de emprego dentro da mesma área (Hickman et al., 2010).

A título de exemplificação, podem ser propostos indicadores de acessibilidade, baseados no ambiente construído (AAC), amparados na própria densidade de atividades (como emprego e varejo) disponíveis e/ou que evidenciem o grau de diversidade de atividades existente em dada localidade e/ou que reflitam a facilidade de deslocamento propiciada ao pedestre pelo desenho urbano, como o número ou tamanho de quarteiróes (Rodrigues, 2013). Outra alternativa é usar alguns índices já existentes, como o proposto pelo Institute for Transportation \& Development Policy (ITDP, 2014).

Localidades onde esses indicadores refletem ambientes construídos mais compactos, diversos e conectados tendem a apresentar menor taxa de viagens por automóveis (Handy et al., 2005). Além disso, a perspectiva da rua para todos (complete street), onde a via é traçada para promover o deslocamento seguro de todos os seus usuários, também pode contribuir com a redução dos deslocamentos motorizados quando provê diferentes opçóes de transporte para a realização de viagens mais curtas, promovendo o transporte ativo (Laplante. \& Mccann, 2008; Shu, Quiros, Wang \& Zhu, 2014).

A proximidade entre pessoas-atividades e a facilidade de deslocamento por modos náo motorizados alicerçam a mobilidade sustentável no nível microscópico, que também pode ser beneficiada pelo nível de restrição adequado no uso de automóveis $\left(A_{R A 2}^{i}\right)$, possibilitando o uso deste indicador também para esta escala.

Considerando que as escalas global e local apresentam demandas distintas em relação à disponibilidade de atividades e serviços assim como de infraestrutura de transportes, o planejamento e, por conseguinte, a implementação de projetos, sintonizados com as metas de desenvolvimento e de mobilidade sustentáveis, precisam vislumbrar tais diferenças (Zegras, 2005; Balta et al., 2012; Libardi, 2014; Rivas, 2014) para que possam ser traduzidas em estratégias potenciais.

\section{Uma estrutura esquematizada do procedimento proposto}

A partir da concepção da abordagem baseada na acessibilidade orientada à mobilidade sustentável e levando-se em conta as especificidades brasileiras, apresenta-se a estruturação esquematizada do procedimento proposto (figura 4), considerando princípios universais, como o direito à vida e com qualidade, justiça e inclusão social em um ambiente preservado, inclusive para as geraçóes futuras (Nascimento, 
2012). Assim como, a mobilidade sustentável a ser contemplada pelos padróes de acessibilidade proporcionados pela infraestrutura e serviços de transportes de forma articulada ao uso do solo.

FIGURA 4 Estrutura do procedimento proposto

PLANO DE MOBILIDADE baseado na ACESSIBILIDADE orientado a SUSTENTABILIDADE: princípios e diretrizes

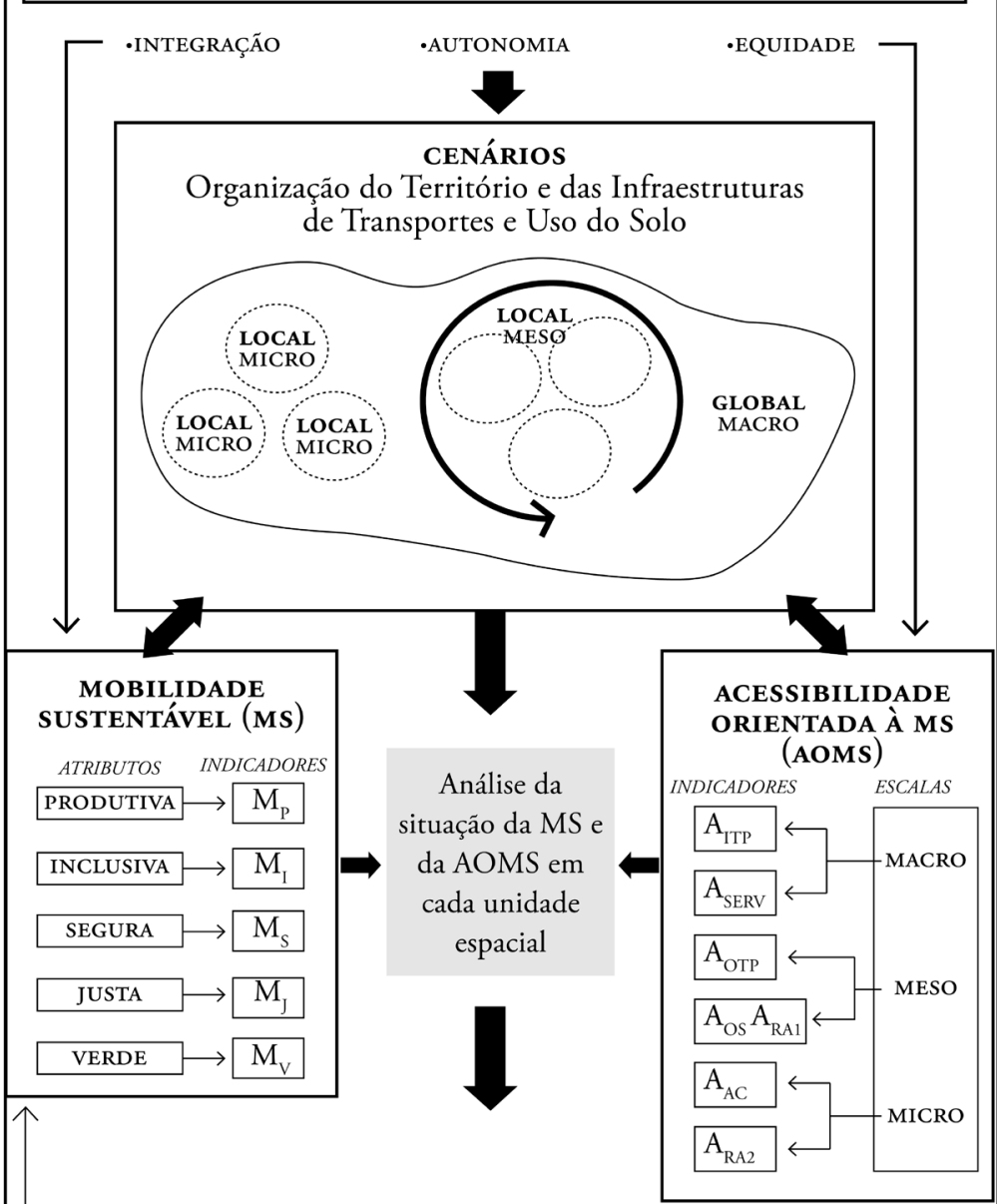

ESTRATÉGIAS DIRECCIONADAS À AOMS NAS UE CRÍTICAS

-ESCALAS -MODAlidades DE TRANSPORTE - USO DO SOlO

Global e Local Motorizada de alta, media e/ou Distribuçáo Macro, Meso, Micro baixa capacidade geográfica de Náo motorizada atividades - serviços - oportunidades 
Nesse processo, o principal desafio é o de sistematizar e organizar o conhecimento segundo uma estrutura que conduza a promoção de condiçóes e estratégias associadas à acessibilidade comprometidas com a mobilidade sustentável. E mais, que esta estrutura e as ferramentas empregadas incentivem análises e decisóes amparadas por ambientes transparentes e participativos.

Em síntese, tal estrutura recomenda, em conformidade com as diretrizes de planejamento urbano integrado, conceber, por um lado, os atributos e indicadores de mobilidade sustentável a serem priorizados e alcançados. Por outro, um cenário de organização espacial, segundo escalas territoriais e respectivos indicadores de acessibilidade, que pode promover essa mobilidade.

O desempenho da mobilidade sustentável e da acessibilidade em cada localidade permite conectar estes dois conceitos e estabelecer uma base para a determinaçáo de possíveis estratégias, definidas quanto: (i) a escala territorial a sofrer intervenção; (ii) os locais mais críticos e que requerem açóes corretivas na acessibilidade; (iii) a natureza das intervençóes, se orientada aos transportes e/ou ao uso do solo; (iv) se aos transportes, em que modalidade (melhorando o transporte público e o não motorizado - inclusive o deslocamento dos cadeirantes - e restringindo a utilizaçáo do automóvel); (v) se uso de solo (por meio de adensamento e diversificação do uso do solo, tipos de atividades a serem considerados).

$\mathrm{Na}$ medida em que a acessibilidade pode ser seletiva, o desempenho dos indicadores da mobilidade e da acessibilidade permitirá definir a natureza e a intensidade das estratégias destinadas a melhorar a mobilidade urbana. Diferentes estudos (uitp, 2003; Geurs \& Wee, 2004; European Commission, 2013; Litman, 2015) investigam tais estratégias e devem ser consultados para auxiliar na identificação das mais adequadas. Isso, sem desconsiderar o abismo entre as análises dos países emergentes e os países desenvolvidos (UN-Habitat, 2013), pois a complexidade dos projetos bem sucedidos nos últimos dificilmente será alcançada naqueles que ainda não apresentam maturidade no planejamento de transportes (Libardi, 2014).

A acessibilidade pode, portanto: favorecer ou não um local, um segmento socioeconômico, uma modalidade e/ou uma dada atividade. E o desempenho dos indicadores de mobilidade e de acessibilidade de uma localidade ampara estratégias potencialmente adequadas e direcionadas à acessibilidade, propensas a promoção da mobilidade sustentável, desejavelmente com a participação de diferentes saberes e setores, estimulando a visão de conjunto, integrada e intersetorial.

Vale ressaltar que essa formulação corrobora com as perspectivas segundo as quais é possível e necessário influenciar novas tendências de comportamento com base na oferta de infraestrutura (Herce, 2009; Rivas, 2014); ter um sistema de transporte urbano integrado, onde os diversos modais se complementam entre si; compatibilizar o planejamento dos transportes e o planejamento do uso do solo, reconhecendo a interdependência existente entre os mesmos; e prover acessibilidade adequada para todos através de um planejamento estratégico que atenda as peculiaridades das diversas escalas territoriais existentes. 


\section{Consideraçóes finais}

A revisão bibliográfica confirma que o planejamento dos transportes não pode ocorrer de maneira dissociada do planejamento urbano, sob o risco de enfrentamento de péssimas condiçóes de acessibilidade e de um consequente padrão de mobilidade contrário à sustentabilidade em suas dimensôes econômica, social e ambiental, exigindo reversáo deste quadro.

Nesse contexto está em curso a mudança de paradigma, no qual a mobilidade passa a ser vista também por seus aspectos qualitativos, em que se priorizam os modos de transporte mais amigáveis ao meio ambiente e mais produtivos socialmente, segundo uma concepção integrada.

Essa transformaçáo cria o espaço necessário para que a acessibilidade - amparada em diretrizes de integração, equidade e autonomia, e orientada à mobilidade sustentável - possa ser utilizada como ferramental estratégico. Ou seja, configurando-se adequadamente as condições de acessibilidade, a partir da combinação entre elementos dos transportes e do uso do solo, é possível alterar o padrão de deslocamentos existentes para que se alcance uma mobilidade comprometida com a sustentabilidade. Portanto, há a premissa de que a acessibilidade funciona como um instrumento fundamental para a promoção da mobilidade (Curl et al., 2011) e que, sendo assim, é possível contribuir para regenerar a realidade crítica encontrada em várias regióes metropolitanas.

Embora o procedimento proposto esteja voltado para o transporte de pessoas, o mesmo poderia ser ajustado ao transporte de cargas. Também poderia considerar, de forma mais explícita e detalhada, a infraestrutura viária e a oferta de estacionamento na análise da acessibilidade, permitindo considerar políticas de gerenciamento da mobilidade por meio de restriçóes ao uso do automóvel e de políticas tarifárias que motivassem maior uso do transporte público e do não motorizado. Ainda pode-se contemplar o efeito na mobilidade proveniente das tecnologias de telecomunicação.

Nesse sentido, o procedimento metodológico proposto configura-se como uma abordagem alternativa e complementar às abordagens tradicionais, com o objetivo de apoiar o planejamento estratégico para a concepção de um transporte integrado e promotor da mobilidade e do desenvolvimento sustentáveis no território metropolitano. Dentre os aspectos positivos do referido procedimento estão a utilização de mecanismos menos complexos e custosos, utilizando-se como fundamentos a construção de cenários e de indicadores robustos, incentivando processos decisórios mais participativos e transparentes. Além disso, por focalizar na acessibilidade e por seu razoável potencial seletivo, possibilita a flexibilidade no tratamento de setores e/ou atividades, permitindo a identificaçáo do grau de equidade existente na oferta destes serviços públicos e dos locais mais carentes para reduzir possíveis desigualdades.

Hoje, muitos países, como o Brasil, reconhecem a relevância de se construir planos de mobilidade assentados na perspectiva da sustentabilidade, mas há ainda muita dificuldade de planejamento e de execução, seja por falta de experiência de seus técnicos, seja por falta de recursos especializados e/ou de um marco institucional forte que promova açóes integradas. E esta pode ser considerada uma restrição da presente proposta. A coordenação de políticas públicas integradas 
reforça a necessidade de uma cultura de planejamento, da valorização do corpo técnico e de pesquisa, bem como de um suporte de financiamento capaz de realizar os investimentos necessários em acessibilidade com vistas a atingir a táo desejada mobilidade sustentável.

\section{Agradecimentos}

Ao CNPq e à Rede Ibero-Americana de Estudo em Polos Geradores de Viagens (http://redpgv.coppe.ufrj.br).

\section{Referências bibliográficas}

Abdallah, K. B., Belloumi, M. \& De Wolf, D. (2013). Indicators for sustainable energy development: a multivariate cointegration and causality analysis from Tunisian road transport sector. Renewable and Sustainable Energy Reviews, 25 (Sept.), 34-43. http:// dx.doi.org/10.1016/j.rser.2013.03.066

Adley, S. \& Halden, D. (2013). The New Zealand accessibility analysis methodology. NZ Transport Agency research report 512. https:/www.nzta.govt.nz/assets/resources/ research/reports/512/docs/512.pdf

Azevedo Filho, M. A. N. de \& Rodrigues da Silva, A. N. (2012). Uma avaliação retrospectiva de Belém do Pará sob a ótica da mobilidade sustentável. Transportes, 21(2), 13-20. https://www.revistatransportes.org.br/anpet/article/view/687

Balta, M. O., Tekel, A. \& Tekel, H. I. (2012). Urban development process of built environments in metropolitan areas in Turkey: Case study of Angora Settlement, Ankara. Journal of Urban Planning and Development, 138(1), 70-77. doi: 10.1061/(ASCE)Up.19435444.0000101

Banister, D. (2008). The sustainable mobility paradigm. Transport Policy, 15(2), 73-80. http:// dx.doi.org/10.1016/j.tranpol.2007.10.005

Banister, D. (2011). Cities, mobility and climate change. Journal of Transport Geography, 19(6), 1538-1546. http://dx.doi.org/10.1016/j.jtrangeo.2011.03.009

ONU Hábitat (Programa de las Naciones Unidas para los Asentamientos Humanos) \& CAF (Banco de Desarrollo de América Latina). (2014). Construcción de ciudades más equitativas: políticas públicas para la inclusión en América Latina. Nairobi: ONU Hábitat. http://publicaciones.caf.com/media/39869/construccion_de_ciudades_mas_equitativas_ web0804.pdf

Cascetta, H., Cartenì, A. \& Montanino, M. (2013). A new measure of accessibility based on perceived opportunities. Procedia - Social and Behavioral Sciences, 87, 117-132. doi: 10.1016/j.sbspro.2013.10.598

Cervero, R. (1989). Jobs-housing balancing and regional mobility. Journal of the American PlanningAssociation. 55(2), 136-150.http://dx.doi.org/10.1080/01944368908976014 
Cervero, R. \& Arrington, G. B. (2008). Vehicle trip reduction impacts of transit-oriented housing. Journal of Public Transportation, 11(3), 1-17. doi: 10.5038/2375-0901.11.3.1

Cervero, R., Sarmiento, O., Jacoby, E., Gomes, L. F. \& Neiman, A. (2009). Influences of built environments on walking and cycling: Lessons from Bogotá. International Journal of SustainableTransportation, 3(4), 203-226. http://dx.doi. org/10.1080/15568310802178314

Cervero, R. (2013). Linking urban transport and land use in developing countries. The Journal of Transport and Land Use. 6(1), 7-24. http://dx.doi.org/10.5198/jtlu.v6i1.425

Cheng, J., Bertolini, L. \& Le Clercq, F. (2007). Measuring sustainable accessibility. Transportation Research Record. Journal of the Transportation Research Board, 1, 1625. http://dx.doi.org/10.3141/2017-03

Costa, M. da S. (2008). Um indice de mobilidade urbana sustentável. Tese de Doutorado, Universidade de São Paulo, Escola de Engenharia de São Carlos, Brasil. http://www. teses.usp.br/teses/disponiveis/18/18144/tde-01112008-200521/pt-br.php

Curl, A., Nelson, J. D. \& Anable, J. (2011). Does accessibility planning address what matters? A review of current practice and practitioner perspectives. Research in Transportation Business \& Management 2, 3-11. http://dx.doi.org/10.1016/j.rtbm.2011.07.001

Curtis, C. (2008). Planning for sustainable accessibility: the implementation challenge. Transport Policy, 15(2), 104-112. http://dx.doi.org/10.1016/j.tranpol.2007.10.003

Delbosc, A. \& Currie, G. (2011). The spatial context of transport disadvantage, social exclusion and well-being. Journal of Transport Geography, 19(6), 1130-1137. http://dx.doi. org/10.1016/j.jtrangeo.2011.04.005

Department of Rail and Public Transportation (DRPT). (2013). Multimodal system design guidelines. The Commonwealth of Virginia, Us: DRPT. http://www.drpt.virginia.gov/ media/1055/drpt_mmsdg_final_full.pdf

European Commission (EU). (2013). Study to support an impact assessment of the urban mobility package. Activity 31 sustainable urban mobility plans. Final Report. COWI, ECORYs and CENIT. http://ec.europa.eu/transport/themes/urban/studies/doc/2013-10-urban-mobilitypackage-activity-31.pdf

European Union (Eu). (2014). Guidelines. Developing and implementing a sustainable urban mobility plan. Brussels: European Union. http://www.eltis.org/sites/eltis/files/ guidelines-developing-and-implementing-a-sump_final_web_jan2014b.pdf

Farrington, J. \& Farrington, C. (2005). Rural accessibility, social inclusion and social justice: Towards conceptualisation. Journal of Transport Geography, 13(1), 1-12. http://dx.doi. org/10.1016/j.jtrangeo.2004.10.002

FERSI/ECTRI (Forum of European Road Safety Research Institutes/European Conference of Transport Research Institutes). (2009). The sustainable safety approach to road transport and mobility. Road Safety Roadmap. Final Version. http://www.ectri.org/ Documents/Publications/Strategic-documents/The-sustainable-safety-approach-toRoad-Transport-and-Mobility_Final.pdf

Fierek, S. \& Zak, J. (2012). Planning of an integrated urban transportation system based on macro-simulation and MсDM/A methods. Procedia - Social and Behavioral Sciences, 54, 567-579. http://dx.doi.org/10.1016/j.sbspro.2012.09.774 
Fouracre, P. R., Sohail, M. \& Cavill, S. (2006). A participatory approach to urban transport planning in developing countries. Transportation Planning and Technology, 29(4), 313330. http://dx.doi.org/10.1080/03081060600905665

Franceschini, S. \& Marletto, G. (2014) A deliberative-participative procedure for sustainable urban mobility - Findings on a test in Bary (Italy). Working Paper. Centre for North South Economic Research (CRENOS). http://crenos.unica.it/crenos/sites/default/files/ WP14-08_0.pdf

Frederico, C. de S. (2001). Do planejamento tradicional de transporte ao moderno plano integrado de transportes urbanos. São Paulo em Perspectiva, 15(1), 45-54. http:// dx.doi.org/10.1590/S0102-88392001000100006

Gemelli, I. M. P. \& Filippim, E. S. (2010). Gestão de pessoas na administração pública: o desafio dos municípios. RACE, Unoesc, 9(1-2), 153-180. http://editora.unoesc.edu.br/ index.php/race/article/view/375

Geurs, K.T. \& Wee, B. V. (2004). Accessibility evaluation of land-use and transport strategies: Review and research directions. Journal of Transport Geography, 12(2), 127-140. http:// dx.doi.org/10.1016/j.jtrangeo.2003.10.005

GIZ (2014). Urban Mobility Plans: National Approaches and Local Practice. Deutshe Gesellschaft für Internationale Zusammenarbeit (GIz) GmbH. Germany. http://bit.ly/2bVEGqK

Gonçalves, J. A. M., Portugal, L. S. \& Nassi, C. D. (2009). Centrality indicators as an instrument to evaluate the integration of urban equipment in the area of influence of a rail corridor. Transportation Research Part A: Policy and Practice. 43(1), 13-25. http:// dx.doi.org/10.1016/j.tra.2008.06.010

Gordon, P., Kumar, A. \& Richardson, H. W. (1989). The influence of metropolitan spatial structure on commuting time. Journal of Urban Economics, 26, 138-151. http://bit. ly/2bjZ1rq

Gouvêa, R. G. (2009). Diretrizes para a gestão metropolitana no Brasil. EURE, 35(104), 47 76. http://dx.doi.org/10.4067/S0250-71612009000100003

Halden, D. (2002). Using accessibility measures to integrate land use and transport policy in Edinburgh and Lothians. Transport Policy, 9(4), 313-324.

Handy, S. L. \& Niemeier, D.A. (1997). Measuring accessibility: An exploration of issues and alternatives. Environment and Planning A, 29(7), 1175-1194. doi: 10.1068/a291175

Handy, S., Cao, X. \& Mokhtarian, P. (2005). Correlation or causality between the built environment and travel behavior? Evidence from Northern California. Transportation Research Part D, 10(6), 427-444. http://dx.doi.org/10.1016/j.trd.2005.05.002

Hansen, W. G. (1959). How accessibility shapes land use. Journal of the American Institute of Planners, 25(1), 73-76. http://dx.doi.org/10.1080/01944365908978307

Herce, M. (2009). Sobre la movilidad en la ciudad: propuestas para recuperar un derecho ciudadano. Barcelona: Reverté.

Hickman, R., Seaborn, C., Headicar, P. \& Banister, D./Association for European Transport and Contributors (2010). Planning for sustainable travel: Integrating spatial planning and transport. In M. Givoni \& D. Banister (Eds.), Integrated Transport (pp. 33-54). Abingdon, uk: Taylor \& Francis. http://abstracts.aetransport.org/paper/download/ $\mathrm{id} / 3300$ 
Hull, A. (2005). Integrated transport planning in the UK: From concept to reality. Journal of Transport Geography, 13(4), 318-328. http://dx.doi.org/10.1016/j. jtrangeo.2004.12.002

Iacono, M., Krizek, K. J. \& El-Geneidy, A. (2010). Measuring non-motorized accessibility: Issues, alternatives and execution. Journal of Transport Geography, 18(1), 133-140. http://dx.doi.org/10.1016/j.jtrangeo.2009.02.002

IMTT (Instituto da Mobilidade e dos Transportes Terrestres), Portugal. (2011). Guião Orientador: Acessibilidades, mobilidade e transportes nos planos municipais de ordenamento do território. Lisboa: Instituto da Mobilidade e dos Transportes Terrestres, Ministério do Planeamento e das Infraestruturas, Programa Nacional da Política de Ordenamento do Território. http://server21.abstractdns.com/ - transpor/ conferenciamobilidade/tema2.php

ITDP (Institute for Transportation and Development Policy), USA. (2014). TOD Standard [Online]. Nova Iorque: ITDP. https://www.itdp.org/tod-standard/

Jeon, G. M., Amekudzi, A. A. \& Guensler, R. L. (2013). Sustainability assessment at the transportation planning level: Performance measures and indexes. Transport Policy, 25, 10-21. http://dx.doi.org/10.1016/j.tranpol.2012.10.004

Jeppesen, S. L. (2009). Sustainable transport planning: A multi-methodology approach to decision making. Tese de Doutorado, DTU Transport - Department of Transport, Technical University of Denmark.

Jones, P. \& Lucas, K. (2012). Social impacts and equity issues in transport: An introduction. Journal of Transport Geography, 21, 1-3. doi: 10.1016/j.jtrangeo.2012.01.032

Kane, L. \& Del Mistro, R. (2003). Changes in transport planning policy: Changes in transport planning methodology? Transportation, 30, 113-131. doi:10.1023/A:1022562125856

Laplante, J. \& Mccann, B. (2008). Complete streets: We can get there from here. Institute of transportation Engineers Journal, 78(5), 24-29.

Levine, J., Grengs, J., Shen, Q. \& Shen, Q. (2012). Does accessibility require density or speed? Journal of the American Planning Association, 78(2), 156-172. http://dx.doi.org/10.10 80/01944363.2012.677119

Levinson, D. M. (2012). Network structure and city size. PloS ONE, 7(1), e29721. http:// dx.doi.org/10.1371/journal.pone.0029721

Libardi, R. (2014). Mobilidade urbana frente a complexidade urbana. EURE, 40(121), 273276. http://dx.doi.org/10.4067/S0250-71612014000300013

Litman, T. (2008). Win-win transportation solutions. Victoria, Canadá: Victoria Transport Policy Institute. http://www.vtpi.org/winwin.pdf

Litman, T. (2009). Where we want to be - Home location preferences and their implications for smart growth. Victoria, Canadá: Victoria Transport Policy Institute. http://www.vtpi. org/sgcp.pdf

Litman, T. (2011). Measuring transportation: Traffc, mobility and accessibility. Victoria, Canadá: Victoria Transport Policy Institute. http://www.vtpi.org/measure.pdf

Litman, T. (2015). Evaluating accessibility for transportation planning measuring people's ability to reach desired goods and activities. Victoria, Canadá: Victoria Transport Policy Institute.

Litman, T. \& Brenman, M. (2012). A new social equity agenda for sustainable transportation. Victoria, Canadá: Victoria Transport Policy Institute. http://www.vtpi.org/ equityagenda.pdf 
Litman, T. \& Fitzroy, S. (2015). Safe travels: evaluating mobility management traffic safety impacts. Victoria, Canadá: Victoria Transport Policy Institute. http://www.vtpi.org/ safetrav.pdf

Machado, L. (2010). Índice de mobilidade sustentável para avaliar a qualidade de vida urbana - estudo de caso: Regiáo Metropolitana de Porto Alegre (RMPA). Dissertação de Mestrado, Universidade Federal do Rio Grande do Sul, Brasil. http://hdl.handle. net/10183/27850

Martens, K. (2006). Basing transport planning on principles of social justice. Berkeley Planning Journal, 19(1), 4-17. http://escholarship.org/uc/item/0tg6v7tn\#page-1

Mavoa, S., Witten, K., McCreanor, T. \& O'Sullivan, D. (2012). gis based destination accessibility via public transit and walking in Auckland, New Zealand. Journal of Transport Geography, 20, 15-22. http://dx.doi.org/10.1016/j.jtrangeo.2011.10.001

Ministério das Cidades, Brasil. (2006). Gestão Integrada da Mobilidade Urbana: Curso de Capacitação. Brasília: Programa Nacional de Capacitação das Cidades, Secretaria Nacional de Transporte e da Mobilidade Urbana, Ministério das Cidades. http:// livrozilla.com/doc/672875/curso-de-gest\%C3\%A3o-integrada-da-mobilidade-urbana

Ministério das Cidades, Brasil. (2015). PlanMob - Caderno de Referência para Elaboração de Plano de Mobilidade Urbana. Brasília: Secretaria Nacional de Transporte e da Mobilidade Urbana, Ministério das Cidades. http://www.cidades.gov.br/images/ stories/ArquivosSE/planmob.pdf

Motte-Baumvol, B. \& Nassi, C.N. (2012). Immobility in Rio de Janeiro, beyond poverty. Journal of Transport Geography, 24, 67-76. http://dx.doi.org/10.1016/j.jtrangeo.2012.06.012

Nascimento, E. P. do. (2012). Trajetória da sustentabilidade: do ambiental ao social, do social ao econômico. Estudos Avançados, 26(74), 51-64. http://dx.doi.org/10.1590/S010340142012000100005

Nelldal, B. L. \& Andersson, E. (2011). Mode shift as a measure to reduce greenhouse gas emissions. Procedia - Social and Behaviorial Sciences - Transport Research Arena (Athens, 2012), 1-11. http://dx.doi.org/10.1016/j.sbspro.2012.06.1285

New South Wales (Nsw) Government. (2013). Integrated Public Transport Service Planning Guidelines - Sydney Metropolitan Area. Sidney, Australia: Nsw Government, Transport for NSw.

onU-Habitat (Programa de las Naciones Unidas para los Asentamientos Humanos). (2013). Planificación y diseño de una movilidad urbana sostenible: Orientaciones para politicas: Informe mundial sobre asentamientos humanos 2013 [Resumen Ejecutivo]. Nova Iorque: oNu-Habitat/Routledge. http://mirror.unhabitat.org/pmss/listItemDetails. aspx?publicationID $=3501$

ONU Hábitat (Programa de las Naciones Unidas para los Asentamientos Humanos) \& CAF (Banco de Desarrollo de América Latina). (2014). Construcción de ciudades más equitativas: politicas públicas para la inclusión en América Latina. Nairobi: ONU Hábitat/CAF. http://publicaciones.caf.com/media/39869/construccion_de_ciudades_ mas_equitativas_web0804.pdf

Parthasarathi, P. (2014). Network structure and metropolitan mobility. The Journal of Transport and Land Use, 7(2), 153-170. https://www.jtlu.org/index.php/jtlu/article/view/494 
PNUD (Programa de Naciones Unidas para el Desarrollo). (2010). Informe regional sobre desarrollo humano para América Latina y el Caribe 2010: Actuar sobre el futuro: romper la transmisión intergeneracional de la desigualdad. San José, Costa Rica: PNUD. http:// hdr.undp.org/sites/default/files/rhdr-2010-rblac.pdf

PNUd (Programa das Naçóes Unidas para o Desenvolvimento). (2014). Atlas do desenvolvimento humano nas regiöes metropolitanas brasileiras. Série Atlas do Desenvolvimento Humano no Brasil. Brasília: pNud, IPEA (Instituto de Pesquisa Económica Aplicada), FJP (Fundação João Pinheiro). http://www.pnud.org.br/arquivos/AtlasdoDesenvolvimen toHumanonasRegi\%C3\%B5esMetropolitanas.pdf

Pochmann, M (2010). Pobreza, desemprego e desigualdade: Anotaçóes importantes sobre o cenário recente no Brasil metropolitano. In M. F. Pinheiro Coelho, L. M. de Souza Tapajós \& M. Rodrigues (Orgs.), Políticas sociais para o desenvolvimento: Superar a pobreza e promover a inclusão (pp. 127-151). Brasília: Ministério do Desenvolvimento Social e Combate à Fome / unesco. http://unesdoc.unesco.org/ images/0019/001907/190752por.pdf

Portugal, L. S., Florez, J. \& Silva, A. N. R. (2010). Rede de pesquisa em transportes: um instrumento de transformação e melhora da qualidade de vida. Transportes, 18, 6-16. http://dx.doi.org/10.14295/transportes.v18i1.395

Porter, C. D., Brown, A., DeFlorio, J., McKenzie, E., Tao, W. \& Vimmerstedt, L. (2013). Effects of travel reduction and efficient driving on transportation: Energy use and greenhouse gas emissions. Transportation Energy Future Series. Oak Ridge, TN: us Department of Energy. http://www.nrel.gov/docs/fy13osti/55635.pdf

Potter, S. \& Skinner, M. J. (2000). On transport integration: a contribution to better understanding. Futures, 32(3-4), 275-287. http://dx.doi.org/10.1016/S00163287(99)00097-X

Raia Jr., A. A. (2000). Acessibilidade e mobilidade na estimativa de um indice de potencial de viagens utilizando Redes Neurais Artificiais e Sistemas de Informaçōes Geográficas. Tese de Doutorado, Universidade de São Paulo. Escola de Engenharia de São Carlos, Brasil. http://www.teses.usp.br/teses/disponiveis/18/18137/tde-10112001-160812/pt-br.php

Reggiani, A., Bucci, P., Russo, G., Haas, A. \& Nijkamp, P. (2011). Regional labour markets and job accessibility in City Network systems in Germany. Journal of Transport Geography, 19(4), 528-536. http://dx.doi.org/10.1016/j.jtrangeo.2010.05.008

Ribeiro, L. C. Q., Silva, E. T. \& Rodrigues, J. M. (2014). As metrópoles brasileiras: entre a concentração e a dispersão. XIII Seminário da Rede Iberoamericana de Investigadores (RII). Salvador, Bahia, 1-4 setembro, 2014. http://bit.ly/2c1yEbq

Rivas, G.S. (2014). Hacia una nueva consideración de las Infraestructuras del Transporte en el Planeamiento Territorial. XI Congreso de Ingeniería del Transporte "El camino hacia el progreso" (CIT 2014). Santander, Espanha, 9-11 junio 2014.

Rodrigues, A. R. P. (2013). A mobilidade dos pedestres e a influência da configuração da rede de caminhos. Dissertação de Mestrado, Universidade Federal do Rio de Janeiro, Brasil.

Rodrigues da Silva, A. N., Azevedo Filho, M. A. N. Macêdo, M. H., Sorratini, J. A., Da Silva, A. F., Lima, J. P. \& Pinheiro, A. M. G. S. (2015). A comparative evaluation of mobility conditions in selected cities of the five Brazilian regions. Transport Policy, 37, 147-156. http://dx.doi.org/10.1016/j.tranpol.2014.10.017 
Rolnik, R. (2013). Apresentação: As vozes das ruas: as revoltas de junho e suas interpretaçóes. In vv.AA., Cidades Rebeldes - Passe Livre e as manifestaçōes que tomaram as ruas do Brasil. São Paulo: Boitempo.

Rubim, B. \& Leitáo, S. (2013). O plano de mobilidade urbana e o futuro das cidades. Estudos Avançados, 27(79), 55-66. http://dx.doi.org/10.1590/S0103-40142013000300005

Seabra, L. O., Taco, P. W. G. \& Dominguez, E. M. (2013). Sustentabilidade em transportes: do conceito às políticas públicas de mobilidade urbana. Revista dos Transportes Públicos - ANTP, 35(2º quadrimestre), 103-124.

Shu, S., Quiros, D. C., Wang, R. \& Zhu, Y. (2014). Changes of street use and on-road air quality before and after complete street retrofit: An exploratory case study in Santa Monica, California. Transportation Research Part D, 32, 387-396. http://dx.doi. org/10.1016/j.trd.2014.08.024

Silva, G. \& Romero, M. (2015). Sustentabilidade urbana aplicada: Análise dos processos de dispersão, densidade e uso e ocupação do solo para a cidade de Cuiabá, Estado de Mato Grosso, Brasil. EURE, 41(122), 209-237. http://dx.doi.org/10.4067/S025071612015000100010

Somik, V. L. (2013). Planning, connecting, and financing cities - now: Priorities for city leaders. Washington DC: World Bank Group. http://documents.worldbank.org/curated/ en/2013/01/17197253/planning-connecting-financing-cities-now-priorities-cityleaders

Souza, G. A. (2015). Produção do espaço e mobilidade urbana: na contramão da sustentabilidade. Revista Produção e Desenvolvimento, 1(3), 42-51. http://revistas.cefet-rj.br/index. $\mathrm{php} /$ producaoedesenvolvimento/article/view/109

Spiekermann, K., Wegener, M., Kvêtôn, V., Marada, M., Schürmann, C., Biosca, O., Segul, A., Antikainen, H., (...) \& Rosik, P. (2011). TRACC - Transport Accessibility at Regionall Local Scale and Patterns in Europe. Luxembourg: ESPON (European Spatial Planning Observation Network). http://bit.ly/2bohogk

Straatemeier, T. (2008). How to plan for regional accessibility? Transport Policy, 15(2), 127 137. http://dx.doi.org/10.1016/j.tranpol.2007.10.002

UITP (Union Internationale des Transports Publics). (2003). Better urban mobility in developing countries: solutions and good practices. Brussels: UITP.

un-Habitat (United Nations Human Settlement Programme). (2013). Planning and design for sustainable urban mobility. Global Report on Human Settlements Series. Nova Iorque: un-Habitat. http://bit.ly/2bSWeUD

Vasconcellos, E. A. (2000). Transporte urbano nos países em desenvolvimento. Reflexöes e propostas (3a ed.). São Paulo: Annablume.

Vega, A. (2011). A multi-modal approach to sustainable accessibility. A case study for the city of Galway, Ireland. In Proceedings of the Irish Transport Research Network, University College Cork, 31 Ago.-1 Sept. 2011. http://www.itrn.ie/uploads/sesA3_ID116.pdf

Veiga, I. S. (2011). Proposta de modelo conceitual para implantação de gestão compartilhada de serviços de transporte público urbano de pessoas dirigido a um cenário de mobilidade e desenvolvimento sustentável. Tese de Doutorado, Universidade de São Paulo, Escola de Engenharia de São Carlos, Brasil. 
WAPC (Western Australian Planning Commission). (2012). Guidelines for preparation of integrated transport plans. Perth, Western Australia: WAPC. http://www.planning. wa.gov.au/publications/6328.asp

Waddell, P., Ulfarsson, G. F., Franklin, J. P. \& Lobb, J. (2007). Incorporating land use in metropolitan transportation planning. Transportation Research Part A, 41(5), 382-410. http://dx.doi.org/10.1016/j.tra.2006.09.008

Waiselfisz, J. J. (2013). Mapa da Violência 2013: Acidentes de trânsito e motocicletas. Rio de Janeiro: cebela (Centro Brasileiro de Estudos Latino-Americanos)/Flacso-Brasil. http://www.mapadaviolencia.org.br/pdf2013/mapa2013_transito.pdf

Wei, V. F. \& Lovegrove, G. (2012). Sustainable road safety: A new (?) neighbourhood road pattern that saves vru lives. Accident Analysis and Prevention, 44(1), 140-148. http:// dx.doi.org/10.1016/j.aap.2010.12.005

Weiner E. (1997). Urban transportation planning in the United States: A historical overview. ( $5^{\text {th }}$ ed.). Washington, DC: us Department of Transportation. http://www.tongji.edu. $\mathrm{cn} /$-yangdy/utp/utp_top.htm

Welch, T. F. \& Mishra, S. (2013). A measure of equity for public transit connectivity. Journal of Transport Geography, 33, 29-41. http://dx.doi.org/10.1016/j.jtrangeo.2013.09.007

Zegras, P. C. (2005). Sustainable urban mobility: exploring the role of the built environment. Tese de Doutorado, Massachusetts Institute of Technology, Cambridge, MA. https://dspace. mit.edu/handle/1721.1/34170

Zhou, J., Wang, Y. \& Schweitzer, L. (2012). Jobs-housing balance and employer-based travel demand management program returns to scale: Evidence from Los Angeles. Transport Policy, 20, 22-35. http://dx.doi.org/10.1016/j.tranpol.2011.11.003 